\title{
A DANÇA POPULAR NO CONTEXTO DA EDUCAÇÃO FÍSICA: UMA PRÁTICA CRÍTICA E EMANCIPATÓRIA NOS CAMINHOS DO MESTRE GRIOT
}

\author{
Lerrine Marie Tábata Carvalho Schildberg \\ Escola Superior de Cruzeiro - Faculdade Anhanguera de Taubaté \\ lerrine_bale@hotmail.com \\ Rachel Duarte Abdala \\ Universidade de Taubaté \\ rachel.abdala@gmail.com
}

\begin{abstract}
RESUMO
A dança é uma das manifestações mais antigas presentes na humanidade. Ressalta-se também sua presença nos documentos que compõem os currículos e respaldam os educadores nos ambientes educacionais, fator determinante para a efetivação deste estudo que teve como lócus de coleta de dados oficinas escolares efetuadas por um Mestre da cultura tradicional da região do Vale do Paraíba Paulista que desenvolve nas escolas um trabalho educativo pautado na dança popular e nos pressupostos necessários para que essa ação se consolide nos ambientes formais de ensino. Esperase com o estudo suscitar a reflexão acerca da importância do diálogo entre cultura e educação, sendo a dança um campo polissêmico de conhecimento.
\end{abstract}

Palavras-chave: Dança popular. Educação física. Cultura popular.

\section{THE POPULAR DANCE IN THE CONTEXT OF PHYSICAL EDUCATION: A CRITICAL AND EMANCIPATORY PRACTICE, IN THE WAYS OF MASTER GRIOT}

\begin{abstract}
Dance is one of the oldest manifestations present in mankind. It is also emphasized their presence in the documents that make up the curricula and support the educators in the educational environments, a determining factor for the accomplishment of this study that had as a locus of data collection school workshops carried out by a Master of the traditional culture of the Vale do Paraíba region Paulista who develops in schools an educational work based on popular dance and the necessary presuppositions for this action to consolidate in the formal educational environments. It is hoped that the study will stimulate reflection about the importance of the dialogue between culture and education, with dance being a polysemic field of knowledge.
\end{abstract}

Keywords: Popular dance. Physical education. Popular culture. 


\section{LA DANZA POPULAR EN EL CONTEXTO DE LA EDUCACIÓN FÍSICA: UNA PRÁCTICA CRÍTICA Y EMANCIPATORIA, EN LOS CAMINOS DEL MAESTRO GRIOT}

\section{RESUMEN}

La danza es una de las manifestaciones más antiguas presentes en la humanidad. Se resalta también su presencia en los documentos que componen los currículos y respaldan a los educadores en los ambientes educativos, factor determinante para la efectivización de este estudio que tuvo como locus de recolección de datos talleres escolares efectuados por un Maestro de la cultura tradicional de la región del Valle del Paraíba Paulista que desarrolla en las escuelas un trabajo educativo pautado en la danza popular y en los presupuestos necesarios para que esa acción se consolida en los ambientes formales de enseñanza. Se espera con el estudio suscitar la reflexión acerca de la importancia del diálogo entre cultura y educación, siendo la danza un campo polisémico de conocimiento.

Palabras clave: Danza popular. Educación física. Cultura popular.

\section{UNE DANSE FOLKLORIQUE DANS LE CONTEXTE DE L'ÉDUCATION PHYSIQUE: UNE PRATIQUE CRITIQUE ET ÉMANCIPATRICE, LE MAÎTRE DE FAÇONS GRIOT}

\section{RÉSUMÉ}

La danse est l'une des plus anciennes manifestations présentes dans l'humanité. Ils soulignent également leur présence dans les documents qui constituent les programmes et soutiennent les éducateurs dans les environnements éducatifs, facteur déterminant pour la réalisation de cette étude qui avait pour locus des ateliers de collecte de données menés par un maître de la culture traditionnelle de la région de Vale do Paraíba. Paulista qui développe dans les écoles un travail éducatif basé sur la danse populaire et les présupposés nécessaires pour que cette action se consolide dans les environnements éducatifs formels. On espère que l'étude stimulera la réflexion sur l'importance du dialogue entre culture et éducation, la danse étant un domaine polysémique de la connaissance.

Mots-clés: Danse populaire. Éducation physique. Culture populaire.

"A cultura é um grande universo que caminha ao lado da educação".

(MESTRE PAIZINHO, 2018)

\section{INTRODUÇÃO}

Uma das expressões da cultura popular mais significativas no Brasil é a dança. Esse tipo de manifestação contribui para a consolidar a cultura e caracterizar a identidade cultural. Como manifestação 
corporal a dança é considerada um fenômeno humano. Inserida no contexto educacional, pode ser uma estratégia pedagógica capaz de cooperar agregando diversas possibilidades educativas concernentes às demonstrações corpóreas. Paradoxalmente, são escassos os trabalhos sistematizados e pautados em princípios educativos relacionados à dança, principalmente no que se refere às danças populares.

Para Pozatti (2003), os elementos que devem compor a realização de uma pesquisa conceitos de ciência, arte, educação e tradição - convergem. Desse modo, deveriam dialogar com o objetivo de promover os benefícios das especificidades de cada área.

As danças populares são mencionadas nos documentos que norteiam e respaldam profissionais da área de Educação Física, tais como os Parâmetros Curriculares Nacionais de Educação Física (doravante, PCN-EF). Tal documento tem por objetivo orientar profissionais no que diz respeito à prática pedagógica, acompanhando as mudanças e transformações ocorridas ao longo dos anos. As danças são citadas no referido documento como forma de valorização da cultura popular:

Este bloco de conteúdos inclui as manifestações da cultura corporal que têm como características comuns a intenção de expressão e comunicação mediante gestos e a presença de estímulos sonoros como referência para o movimento corporal. Trata-se das danças e brincadeiras cantadas [...]. Num país em que pulsam o samba, o bumba-meu-boi, o maracatu, o frevo, o afoxé, a catira, o baião, o xote, o xaxado entre muitas outras manifestações, é surpreendente o fato de a Educação Física ter promovido apenas a prática de técnicas de ginástica e (eventualmente) danças europeias e americanas. (BRASIL, 2001, p. 51).

Posteriormente, a dança popular foi incluída de forma mais sistematizada na recém homologada Base Nacional Comum Curricular (BNCC). O documento foi elaborado tendo por meta integrar e articular o ensino em território nacional e sugere a efetivação de práticas relacionadas às danças populares no ciclo I do ensino fundamental, no componente que se refere à disciplina de Educação Física, e nesse contexto, de interlocução entre dança popular e o ambiente educacional, situa-se o corpo, responsável por mediar o diálogo corporal. Segundo Nanni (2003), o corpo possui um vocabulário peculiar e expressa uma linguagem predecessora à fala e dá suplemento à linguagem oral. A dança manifesta signos corporais, portanto, os aspectos que remetem ao estudo do corpo no contexto educacional possuem caráter fundamental, pois o:

[...] corpo é uma síntese, porque expressa elementos específicos da sociedade a qual faz parte. O homem, através do seu corpo, vai assimilando e se apropriando dos valores, normas e costumes sociais, num processo de incorporação (a palavra é significativa). Mais do que um aprendizado intelectual, o indivíduo adquire um 
conteúdo cultural, que se instala no seu corpo, no conjunto de suas expressões. (DAOLIO, 1995, p. 25).

São raras as iniciativas que envolvem o conteúdo relacionado à dança nas escolas, sobretudo de propriedade afrodiaspóricas. A proposição metodológica para o desdobramento de intervenções pedagógicas destinadas à utilização e à disseminação dos bens culturais promovem uma experiência multidimensional, para tanto, estas práticas aplicadas aos conteúdos relacionados à cultura corporal do movimento, neste caso, a dança, é de extrema significância. Nessa perspectiva é importante projetar e organizar espaços que dão voz para o patrimônio educativo e concomitantemente valorizem o trabalho interdisciplinar, sendo a dança um campo polissêmico de saberes.

\section{A DANÇA POPULAR: PATRIMÔNIO IMATERIAL, POSSIBILIDADES NO CONTEXTO EDUCATIVO}

A concepção de patrimônio cultural, a princípio, considerava apenas aspectos relacionados a sítios arquitetônicos, desconsiderando a concepção imaterial que contempla as manifestações provenientes da cultura corporal do movimento. Contudo, as reflexões evoluíram, percebeu-se nessas observações o quão diverso e abrangente é a concepção de patrimônio. São estabelecidos como patrimônios culturais, conteúdos relacionados à relevância histórica e expressões culturais como a dança, culinárias peculiares, fazeres e costumes em geral.

As iniciativas que envolvem a dança popular deveriam ser mais exploradas nas aulas de Educação Física; é necessário romper com a visão dicotômica que circunda a educação formal e a cultura popular. Foi nesse contexto de pesquisa e inquietação, observação e busca de inovações, que tivemos o privilégio de conhecer Mestre Paizinho e seu trabalho. Essa temática repleta de possibilidades viabiliza no espaço escolar a preservação do Patrimônio Cultural Imaterial Regional no Brasil.

\section{PERCURSO METODOLÓGICO}

Geraldo de Paula Santana, Mestre Paizinho, é respeitado como mestre de cultura nos círculos culturais tradicionais do Vale do Paraíba Paulista, região situada a Leste do Estado de São Paulo e a Oeste do Rio de Janeiro, marcada pelo ciclo do café, possui em sua história uma forte 
relação com manifestações culturais como a Congada, o Moçambique e o Jongo. Essas danças consideradas Festas de Sobrevivência Histórica dos negros, trazem consigo a responsabilidade de manifestar a história permeada pela angústia e resistência dos negros escravizados nessa região. Tais manifestações devem ser compreendidas neste contexto, considerando o lugar em que elas despontam e como nascem na sociedade. Na mesma proporção em que os brancos dominavam e inseriam a religião oficial e conviviam dentro das instituições religiosas, os afrodescendentes permaneciam nas ruas e senzalas com seus instrumentos musicais, adereços e danças. A dança, poesia anunciada pelo corpo, nesse contexto, é a fé em movimento que resiste, e com ela cânticos de labuta e da vida desses povos. Nesse percurso de luta e resistência Mestre Paizinho confronta o tempo, a contemporaneidade, a insolência, o preconceito e o descaso ensejado pelas políticas públicas.

Mestre Paizinho é considerado por muitos um Griot da dança popular; sobre o ofício dos Griots:

O termo griot, na cultura africana, significa contador de histórias, função designada ao ancião de uma tribo, conhecido por sua sabedoria e transmissão de conhecimento; figura presente na África tribal que percorre a savana para transmitir, oralmente, ao povo fatos de sua história; é o agente responsável pela manutenção da tradição oral dos povos africanos, cantada, dançada e contada através dos mitos, das lendas, das cantigas, das danças e das canções épicas; é ele que mantém a continuidade da tradição oral, a fonte de saberes e ensinamentos e que possibilita a integração de homens e mulheres, adultos e crianças no espaço e no tempo e nas tradições; é o poeta, o mestre, o estudioso, o músico, o dançarino, o conselheiro, o preservador da palavra. (MELO, 2009, p. 149).

Sem dúvidas, pode-se comparar Mestre Paizinho a um Griot da atualidade. Mesmo considerando o advento contemporaneidade como uma aniquiladora de tradições, ele resiste, por meio de suas canções adaptadas e relacionadas ao currículo escolar, instrumentos e gestualidade. Mestre Paizinho, conduz uma reflexão sobre questões importantes acerca da identidade cultural regional desenvolvendo o ofício transmitido por seus antepassados e entregando à sociedade um trabalho de extrema relevância. Legatário de Mestre Paizão, seu pai biológico, lidera uma Companhia de Moçambique de São Benedito, cuja história iniciou-se há mais de cem anos, perpassando gerações. O grupo liderado por Mestre Paizinho tornou-se referência nacional de perpetuação da ancestralidade, memória, identidade e disseminação da cultura popular regional. Entretanto, esse mestre possui um diferencial, o seu trabalho não se resume apenas à comunidade cultural. Mestre Paizinho desenvolve um trabalho nas escolas e ministra oficinas de Moçambique 
em diversas instituições de ensino. Quando indagado sobre sua formação profissional e atuação ele responde: “Eu tenho o terceiro ano do colegial incompleto, minha profissão é: Mestre da cultura popular”. (MESTRE PAIZINHO).

Tais manifestações locais congregam maneiras de ser e agir características da população caipira, expressando representações e práticas culturais que dialogam com aspectos religiosos do cotidiano popular. De maneira geral, observa-se uma certa invisibilidade, uma distância e um silenciamento em relação a manifestações populares; essa realidade social, permeada pelo preconceito e desvalorização, legitimam a preferência pelo desporto em detrimento às danças populares nas aulas de Educação Física.

Eu acredito que é pouco trabalhado, são poucos os professores que optam por este caminho, por falta de conhecimento ou por falta de valorização mesmo, ou até mesmo por não ter tido isso, eu acho que poderia ser mais abrangente, pois daria muito mais sentido e significado para as crianças, pois, desenvolveria o indivíduo de forma integral e a identidade do aluno. Mestre Paizinho é para mim um educador por essência, um exemplo para muitos professores, o que ele oferece ninguém tem condições de oferecer, pois ele traz o conhecimento do povo.

(DOCENTE I).

Na narrativa acima é possível observar que existe um distanciamento entre a dança popular e os professores de Educação Física. Mestre Paizinho é um disseminador da tradição capaz de fomentar a cultura na escola.

O Mestre afirma que seu ofício é o de perpetuar esses saberes para que eles não sejam extintos definitivamente. Entretanto, como foi possível observar, o legado do mestre possui um diferencial: ele não se restringe às comunidades culturais. Sua missão, termo por ele utilizado em conversa informal, é a de disseminar saberes populares por meio das danças nas instituições de ensino, o que o torna uma referência cultural, bem como educacional. Ele é requisitado por educadores de nível e esferas pedagógicas diferenciadas, com o objetivo de propagar tais práticas em instituições de ensino e dar voz para a dança popular, bem como estabelecer um diálogo entre a cultura popular e a educação.

O Mestre, há cerca de vinte anos, ministra oficinas de danças populares pautadas em princípios educativos, nos estabelecimentos de ensino públicos e privados, atendendo a diversas demandas educacionais da região do Vale do Paraíba Paulista. Por meio dessas práticas, ele perpetua saberes culturais dotados de especificidades e ressignificações, respeitando sempre o princípio da escola democrática e laica, só assim a cultura popular consegue adentrar a um universo 
homogeneizador como a escola. Um exemplo de transfiguração são os cânticos adaptados às demandas educacionais: as letras trazem conteúdo lúdico no lugar dos tradicionais temas do catolicismo popular. "A dança do Moçambique é bonita demais é cultura africana é bonita demais, é cultura africana e não esqueço jamais"; dessa forma o ambiente escolar consegue se aproximar efetivamente do cotidiano da cultura popular.

Cada música tem o seu ritmo, então quando o aluno aprendeu a primeira parte, vamos então pro segundo ritmo, terceiro e assim vai. E todo o final tem assim uma parte repetitiva, passando toda musicalidade que a gente passou anteriormente. Todo final, a gente fala: "quem esteve neste lugar, foi o Mestre Paizinho da cultura popular, e a criança quando canta, bom exemplo ela traz.

E tudo isso vai sendo gravado na mente de cada criança, pois no momento que ela entrou para a sala e a professora começou a ensinar a matéria e, principalmente quando eles têm que ir para a aula de artes ou de educação física... "A professora quando ensina, o aluno presta atenção, ela ensina com carinho, muito amor e educação.

Toda a musicalidade que o Mestre Paizinho transmite para o aluno, ele utilizará dentro da sala de aula, no seu dia a dia da convivência familiar, onde que ele estiver! E Moçambique nada mais que é do que para poder fortalecer a educação e direcionar o aluno, porque hoje em dia a gente vê tanta violência, né? Se o aluno, tem aquele momento rico, essa vivência que ele aprendeu com Mestre Paizinho, ele pode usar para o seu dia a dia! (MESTRE PAIZINHO).

Mestre Paizinho não possui incentivo financeiro do Município, ele relata que é muito solicitado pelas escolas do Vale; o Mestre se desloca para as oficinas com sua bicicleta motorizada, doada por um amigo, carregando os bastões de Moçambique na garupa; algumas instituições se sensibilizam e oferecem a ele uma quantia irrisória que ele denomina Cachê, no entanto, a maior parte das instituições não retribuem à altura, ele não recebe por seu trabalho de forma igualitária como os demais educadores.

Com base nas elucidações expostas, o presente estudo propôs a realização de uma pesquisa, por meio de um estudo de caso, esse método adotado por diversas correntes de conhecimento tem por objetivo investigar eventos sociais peculiares. Essa metodologia, que enfatiza a multidimensionalidade presente no contex to do estudo, considera as particularidades contidas em determinados eventos.

O estudo de caso legitima a profundidade nas análises, bem como as exigências contidas nos episódios a serem pesquisados. "Estudo de caso não é uma escolha metodológica, mas uma escolha do objeto a ser estudado" (STAKE, 1994, p.236). Após analisar o contexto no qual seria 
realizada a coleta dos dados, bem como os colaboradores que iriam contribuir, foram considerados, por fim, pequenos detalhes que iriam constituir inúmeras possibilidades. A principal apreensão foi a de não perder minúcias e não descontextualizar os significados. A pesquisa também se preocupou com a poética presente na narrativa dos colaboradores do estudo, bem como com a constituição de dados provenientes de figurinos, fotografias, objetos pessoais, matérias originárias de jornais e revistas. Por essa razão optou-se por utilizar o método pautado na história oral (MEIHY; HOLANDA, 2017) sobre a vida, a prática e as ideias de Geraldo de Paula Santana, Mestre Paizinho, sobre/em suas oficinas de danças populares nas escolas de um município, situado na região do Vale do Paraíba Paulista. Esse trabalho pretende iniciar um desmonte das muralhas entre a cultura popular e a educação, e apresentar possibilidades para que esse diálogo aconteça.

O método denominado história oral, possibilita um diálogo amplo entre os dados obtidos e, neste estudo diversos aspectos foram levados em consideração como mencionados anteriormente. Ressalta-se, portanto, essa possibilidade ampla de abordagens- entrevistas que podem dialogar com documentos, com figurinos, com fotos, viabilizando assim, a compreensão de diversos aspectos de um fenômeno a ser explorado. Tantas nuances, caracterizam a história oral, cujo elemento central, acontece em torno de pessoas, estruturalmente falando a $H . O$ é um método eficaz por sua abordagem pluridimensional.

Neste estudo, devidamente submetido ao comitê de ética, foram abordadas as danças populares que compõem a grade curricular da Educação Física. Para responder aos questionamentos do trabalho, foram realizadas duas entrevistas com o colaborador central da pesquisa, que disponibilizou também um acervo diversificado de materiais fotográficos, documentos e ornamentárias. Para compreender a dinâmica que constituem as oficinas, foram realizadas também observações de campo, obedecendo aos seguintes critérios: contato com estabelecimentos educativos que o Mestre ministrou oficinas no primeiro semestre do ano de dois mil e dezessete - de segundo ao quinto ano do ensino fundamental I, com a finalidade de identificar as peculiaridades contidas nessas vivências. As observações propiciaram um aprofundamento que foi de extrema importância para a pesquisa; foi possível verificar a abrangência e complexidade contidas nas oficinas - estas, continham processo pedagógico, duração de cerca de uma hora e a adesão dos alunos em sua totalidade. Ainda, foram elaboradas entrevistas com a equipe gestora das escolas onde foram efetuadas as observações, que reafirmaram a importância do trabalho desenvolvido pelo Mestre da cultura. 
Posteriormente, a análise das vestes e ornamentárias propiciaram a imersão em um universo profundo e representativo, devido à dimensão simbólica presente nesses materiais; mais do que a função de vestir ou reproduzir um som, como no caso dos instrumentos musicais, esses elementos representam a identidade social de grupos específicos, e a História Oral nesse contexto propicia a análise em profundidade de dados diversos.

FIGURA 1 - Mestre Paizinho e alunos participando da oficina cultura de Moçambique.

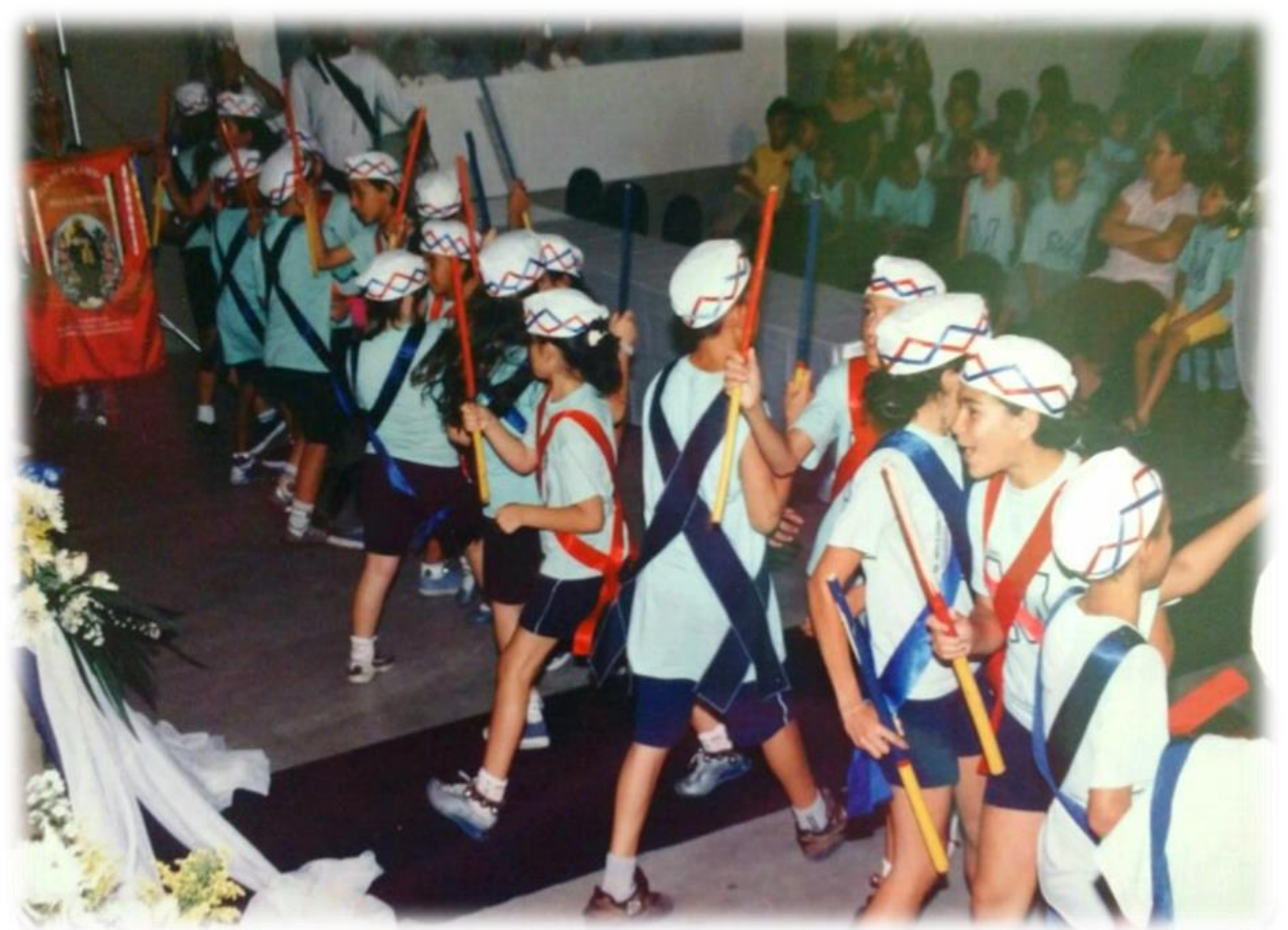

Fonte: Acervo pessoal de Mestre Paizinho

Conforme apresenta a imagem acima, as faixas cruzadas na região do tórax, que fazem menção a São Benedito e a Nossa Senhora do Rosário, na escola, adquirem uma nova conotação: a cor azul representa a paz e a vermelha o amor, os bastões que no Moçambique tradicional representam espadas é o elemento central na composição coreográfica.

O bastão possui grande relevância na prática do Moçambique e é considerado elemento central em relação a ritmicidade na presente manifestação. Realiza-se com bastões, que, além de funcionarem como paus percucientes e entrechocantes para a marcação do ritmo, servem também para formar desenhos no chão, possibilitando o desenvolvimento de várias figurações coreográficas. (RIBEIRO, 1981, p. 59).

Rev. Iberoam. Patrim. Histórico-Educativo, Campinas (SP), v. 5, p. 1-23, e019037, 2019. 
Na cabeça, os moçambiqueiros usam uma espécie de gorro chamado casquete e amarrados aos pés, mini instrumentos denominados guizos, que complementam a composição da ornamentária, Mestre Paizinho, na entrevista, diz que confecciona com as crianças, guizos alternativos desenvolvidos por meio de potes plásticos; é possível observar também a bandeira de São Benedito na imagem, no entanto, ele ressalta que a utilização do mastro não é possível em todas as escolas. Mediante a vasto acervo de informações é que essa pesquisa encontrou na história oral a possibilidade de diálogo entre os dados.

\section{CONVERSANDO SOBRE CULTURA}

A pesquisa acerca da concepção de cultura permite imergir num contexto de controvérsias e ambivalências, cujos termos estão em constante processo de ressignificação; a discussão conceitual é ampla, complexa e abrangente. A dimensão do conceito de cultura provém, inevitavelmente, da densidade e amplitude das perspectivas antropológicas e sociológicas. Em relação à sua origem latina:

[...] a palavra "cultura" passou do cultivo da terra para a cultivação do espírito humano, designando sempre o cuidado com que se faz brotar a semente para produzir uma fartura de alimento- para o corpo ou para a cabeça. A cultura é a síntese por excelência da atividade humana, seja esta, manual ou intelectual. A etimologia da palavra nos mostra que a cultura não é um acaso. Ela é fruto - para usar um termo que remete às suas raízes agrárias. (BOTELHO, 2016, p. 7).

A partir das reflexões propostas por Botelho (2016) pode-se compreender a importância de se aliar os conceitos atrelados à sociologia e à antropologia, tendo em vista promover uma abordagem interdisciplinar interpelando questões discutidas entre as áreas que não podem ser vistas como independentes.

De acordo com as perspectivas da sociedade contemporânea, o objetivo desse estudo é promover o diálogo entre diversas áreas do conhecimento, haja vista que o tema desta pesquisa é promover a discussão entre cultura e educação. Portanto, a visão dicotômica entre as correntes dos saberes deve percorrer os sentidos correspondentes, promovendo, desse modo, um diálogo entre ambas. Tais fronteiras conceituais devem ser superadas. A cultura é o viés capaz de romper essa visão fragmentada entre as perspectivas, possibilitando, sobretudo, a reflexão da interdisciplinaridade contida no campo epistêmico do estudo da cultura.

Rev. Iberoam. Patrim. Histórico-Educativo, Campinas (SP), v. 5, p. 1-23, e019037, 2019. 


\section{A DANÇA MOÇAMBIQUE UM PATRIMÔNIO IMATERIAL DA CULTURA PAULISTA: DOS PÉS NA TERRA AO TERRITÓRIO DA PESQUISA}

A dança Moçambique é uma manifestação da cultura popular tradicional que envolve ritmo, devoção e uma narrativa corporal mediada por conteúdos simbólicos, considerada um patrimônio tradicional imaterial da cultura Paulista. Essa manifestação stabelece um paralelo com as particularidades das raízes brasileiras, dialogando com peculiaridades da região do Vale do Paraíba Paulista, onde esta pesquisa foi elaborada. Para tanto, buscou-se, nas palavras de Baumgratz (2011), além de uma definição para o Moçambique, a defesa de sua importância:

É uma das tradições culturais de matriz africanas mais representativas do Vale do Paraíba Paulista. É uma tradição transmitida de pai para filho. O Moçambique é uma antiga dança, em que se destacam influências indígenas e também europeias ibéricas, como a das danças de bastões dos pauliteiros de Miranda, em Portugal. É considerada dança guerreira, são lembrados os feitos de Carlos Magno e os Doze Pares de França, nas cruzadas dos cristãos contra os mouros e outros inimigos do catolicismo medieval. (BAUMGRATZ, 2011, p. 85).

Pode-se acrescentar ainda que este legado, oriundo da cultura popular, é transmitido pela oralidade. Esta manifestação de origem africana solidificou-se em território brasileiro e originouse nos estados paulistas.

No mundo contemporâneo, pode-se observar uma desconstrução da dança Moçambique, no sentido de adaptação às novas demandas da sociedade pós-moderna, sob influência do "esfacelamento das memórias, as vicissitudes econômicas, as migrações, as diferenças regionais interferiram evidentemente na ordenação, digamos canônica” (MEYER, 2001, p.162).

É possível constatar que a sociedade desqualifica algumas práticas da cultura popular, dentre elas o Moçambique, "confundindo-se com as manifestações culturais dos mais pobres, o que explica porque muito branco, tornando negro pela miséria comum, participe dela” (MEYER, 2001, p.164). No entanto, estas manifestações são dignas de interesse por parte de órgãos relacionados à cultura e folclore ${ }^{1}$ nacionais; tais fragmentos, oriundos da cultura tradicional e, por vezes, desprezados pelo corpo social, são eventualmente os únicos meios de expressão e discurso

\footnotetext{
${ }^{1}$ Vale ressaltar que o termo folclore é considerado pejorativo em relação ao termo cultura popular, os preceitos divergem (MONTEIRO, 2011).
}

Rev. Iberoam. Patrim. Histórico-Educativo, Campinas (SP), v. 5, p. 1-23, e019037, 2019. 
dos afrodescendentes ou classes menos abastadas. Contudo, essa forma de expressão possui invisibilidade por parte da sociedade.

Embora incontestável a complexidade imbuída nos conteúdos referentes a esses discursos corporais, evidencia-se, como supracitado, um silenciamento e até uma indiferença pela sociedade dominante, e a consequência deste desprezo é o desaparecimento dessa manifestação. Todavia, percebe-se, paulatinamente, a importância de se retomar essas práticas, de conformação da identidade negra, como uma possibilidade responsável por perpetuar a identidade nacional. Guiados por tais reflexões pode-se perceber que muitos jovens estão experimentando práticas corporais produzidas na dialética africana e brasileira, promovendo a formação de uma consciência contemporânea com base em um diálogo corporal, promovido pelas manifestações dançantes. $\mathrm{O}$ Moçambique, manifestação da cultura popular que possui significativo valor simbólico para Mestre Paizinho, devido à sua representação relacionada à ancestralidade e tradição que marcaram sua história de vida.

A cultura é o movimento da ancestralidade. A ancestralidade é como um tecido produzido no tear africano: na trama do tear está o horizonte do espaço; na urdidura do tecido está a verticalidade do tempo. Entrelaçando os fios do tempo e do espaço cria-se o tecido do mundo que articula a trama e a urdidura da existência. (OLI VEIRA, 2007, p. 245).

Do latim traditĭo, a tradição é um complexo de propriedades culturais transmitidas de geração em geração no interior de grupos sociais. Concernente a princípios, comportamentos e manifestações que são conservados, pois, são considerados significativos para a sociedade. Nesse contexto ressalta-se a tradição inventada, que se caracteriza pela continuidade da tradição fidedigna, todavia, devido às transformações ocorridas ao longo do tempo é inevitável que as tradições adquiram novos formatos. (HOBSBAWN, 1977). O Moçambique é uma dança considerada uma linguagem da manifestação da cultura popular brasileira, repleto de saberes populares, enunciados por códigos corporais, ornamentários e rítmicos, que são permeados por princípios relacionados à religiosidade e tradição. 
FIGURA 2 - Companhia de São Benedito, liderado por Mestre Paizinho.

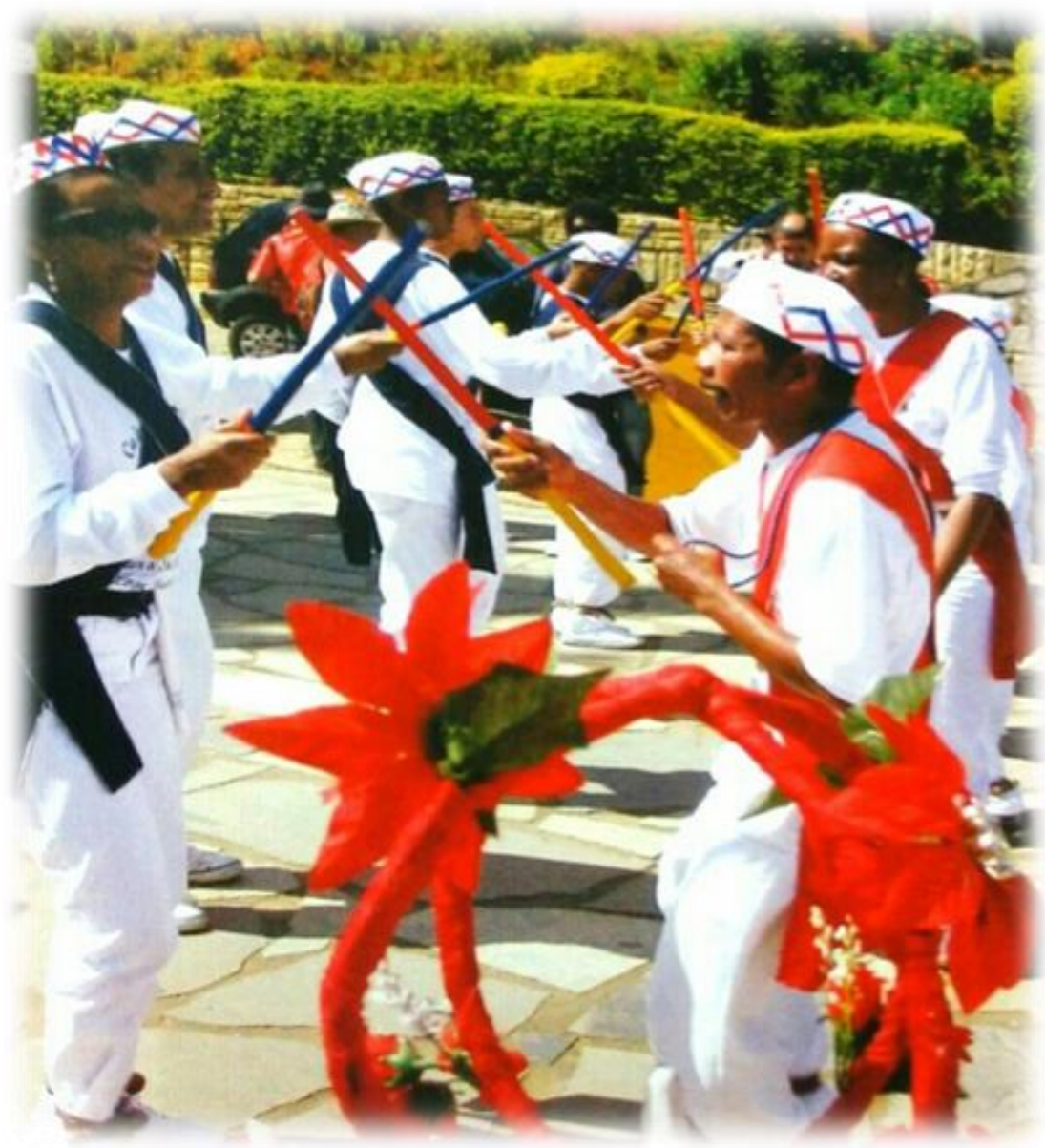

Fonte: Foi são Benedito que nos trouxe até aqui, 2012.

\section{OS DIZERES DO CORPO}

O movimento corporal é denominado universal. Algumas reflexões devem ser apresentadas, dentre elas, a desmistificação da visão positivista e unilateral sobre o conceito de corpo. O corpo deve ser compreendido em sua totalidade, portanto, ressalta-se a relevância do seu papel na construção do processo narrativo por meio da gestualidade. No gesto, uma forma particular de comunicação é exercida, e o corpo é elemento central no processo de subsistência humana. No entanto, essas observações não se esgotam na identificação do indivíduo como sendo um ser apenas anatômico e social. 
A representação corporal ultrapassa o conceito fisiológico e anatômico: o campo simbólico relacionado ao papel social determina as representações significativas do corpo. Como afirma Gomes (2006, p. 261

É no corpo que se dão as sensações, as pressões, os julgamentos. Esses não acontecem de forma independente, mas estão intimamente entrelaçados, constituindo uma estrutura, uma unidade que tem uma ordem - a sua forma de corpo. É essa forma que garante o modo de ser no mundo e torna possível a compreensão de como as relações são construídas com o mundo e no mundo.

O estar no mundo confere ao indivíduo a construção de sua identidade, tal como a composição de sua história de vida. A respeito desta reflexão, Foucault (1979) defende:

Sobre o corpo se encontra o estigma dos acontecimentos passados do mesmo modo que dele nascem os desejos, os desfalecimentos, os erros; nele também eles se atam e de repente se exprimem, mas neles também eles se desatam, entram em luta, se apagam uns aos outros[...] Lugar de dissociação do Eu. (FOUCAULT, 1979, p. 22).

Observando as palavras de Foucault, abstrai-se que é possível compreender o corpo como possibilidade de narrativa gestual, e que este retrata essas vicitudes. É o discurso da linguagem corporal, possíveis por meio da gestualidade, cujas marcas compõem o processo histórico dos indivíduos. Assim, viabilizam-se as possibilidades expressivas, promovidas pelo diálogo entre o corpo e a dança popular, a relação entre cultura popular, dança e educação e as peculiaridades envolvidas neste processo.

\section{NO CHÃO DA EDUCAÇÃO FORMAL}

O que é um sistema de educação formal denominado escola? Para que se compreenda essa questão, é necessário que se aborde de modo sucinto o conceito de educação: “A educação é um fenômeno social, bastante amplo, que ocorre naturalmente nas interações sociais, pois destas resultam aprendizagens" (DARIDO; RANGEL, 2005, p. 51). De acordo com a evolução das instituições sociais, houve a necessidade de se formalizar as organizações exclusivamente dedicadas ao processo de ensino e aprendizagem, as intituladas escolas. Contudo, o processo iniciado em diversas instituições como comunidades sociais, familiares, religiosas, não perderam sua função no processo de composição de educação na vida do indivíduo. 


\section{PARÂMETROS CURRICULARES NACIONAIS E EDUCAÇÃo FÍSICA, NOVOS RUMOS PARA A EDUCAÇÃO FÍSICA?}

Os Parâmetros Curriculares Nacionais (PCN) (BRASIL, 2001) foram produzidos pelo Ministério da Educação Brasileiro na década de noventa com o objetivo de subsidiar a implantação ou revisão curricular nos Estados e Municípios, pós Lei de Diretrizes e Bases. Os PCN possuem especificidades para cada área de conhecimento do currículo escolar.

Após novas perspectivas para o ensino da Educação Física, ocorridos na década de oitenta, foram publicados novos documentos que promoveram certa revolução acerca desse ensino.

Os documentos que norteiam a Educação Física apresentam uma proposta que valoriza a democratização, a humanização e a diversificação da prática pedagógica da área. Conforme proposta apresentada pelos PCN, o conteúdo da Educação Física é dividido por três blocos: Conhecimentos sobre o corpo; Esportes, jogos, lutas e ginásticas; e Atividades rítmicas e expressivas - no qual o conteúdo dança está inserida. De acordo com o documento:

A diversidade cultural que caracteriza o país tem na dança uma de suas expressões mais significativas, constituindo um amplo leque de possibilidades de aprendizagem. Todas as culturas têm algum tipo de manifestação rítmica e/ou expressiva. No Brasil existe uma riqueza muito grande dessas manifestações. Danças trazidas pelos africanos na colonização, danças relativas aos mais diversos rituais, danças que os imigrantes trouxeram em sua bagagem, danças que foram aprendidas com os vizinhos de fronteiras. (BRASIL, 200, p. 52).

Cabe aos docentes, portanto, a responsabilidade de cumprir essas demandas no ambiente educacional, como priorizam os Parâmetros Curriculares Nacionais.

A publicação dos PCN despertou uma nova visão relacionada ao currículo escolar, viabilizando propostas antes desqualificadas e desprezadas pelos profissionais de Educação Física: a valorização da cultura popular por meio das danças.

\section{SERÁ A BASE A BASE?}

A recém-publicada Base Nacional Comum Curricular (BNCC), em dezembro de 2017, é o documento responsável por subsidiar os currículos da educação em território brasileiro. Elaborada por pesquisadores e especialistas de diversas linhas de atuação dos currículos, que compõem a grade de disciplinas do campo educacional, foi direcionada para instituições de ensino público e 
privado e abrange inicialmente a Educação Infantil e o Ensino Fundamental, complementada com a proposta para o Ensino Médio. Esse documento tem por objetivo padronizar e promover uma educação democrática em âmbito nacional.

A Base Nacional Comum Curricular (BNCC) é um documento de caráter normativo que define o conjunto orgânico e progressivo de aprendizagens essenciais que todos os alunos devem desenvolver ao longo das etapas e modalidades da Educação Básica, de modo a que tenham assegurados seus direitos de aprendizagem e desenvolvimento, em conformidade com o que preceitua o Plano Nacional de Educação (PNE). (BRASIL, 2017, p. 7).

Tal proposta é questionada por muitos profissionais que alegam que a BNCC limita a capacidade criativa do profissional de educação, assim como os PCN. Verifica-se também a incoerência de se tentar homogeneizar o ensino respeitando as particularidades regionais; e indagase então: como tornar o ensino igualitário em um país repleto de diversidade cultural? Conclui-se que, o documento deveria levar à reflexão sobre uma proposta norteadora e não incisiva e obrigatória, mas considera-se o compromisso enfatizado pelo documento: a melhoria da educação.

\section{NOS PASSOS DO GRIOT DA CULTURA POPULAR: MEMÓRIA, MISSÃo, EDUCAÇÃO E PERCALÇOS}

Mestre Paizinho, assim intitulado, devido à relação de seu pai, Mestre Paizão, com a cultura popular, possui uma trajetória pautada na ancestralidade e na teimosia. Ele faz das oficinas de danças populares na Escola sua missão.

O nosso Moçambique teve como ponto de partida, com o meu saudoso pai, Geraldo de Paula Santana, mas todo mundo chamava ele de Mestre Paizão, pois ele tinha 1,98. E eu era o chaveirinho (risos). Nossa história começou em 1947, eu, com 5 anos de idade, comecei a participar ao lado do meu pai, com 5 anos e hoje eu tenho 51. Tem 48 anos que eu me dedico ao Moçambique. Mas eu ainda me considero como um aprendiz, pois mesmo sendo um mestre... pois a vida, a cada dia, coloca novos desafios e a gente tem que aprender com eles, e nunca passar por cima e sim ver onde aquele desafio está mostrando o que a gente pode aprender. (MESTRE PAIZINHO).

E apesar de desenvolver um trabalho eloquente e singular em estabelecimentos formais de educação, muitos são os desafios e obstáculos encontrados por ele, segundo sua narrativa. Dentre eles, encontra-se o cenário político nacional atual, cuja perspectiva culmina na proposta de 
atividades que não dialogam com a teoria pós-crítica que embasa as aulas de Educação Física no contexto contemporâneo. Tal teoria, rompe com modelos de ensino militaristas que direcionavam a prática e o exercício do profissional de Educação Física, que outrora, reproduzia os movimentos, sem, no entanto, refletir sobre os mesmos. Na atualidade utiliza-se a cultura corporal do movimento como meio para se refletir sobre a prática.

FIGURA 3 - Mestre Paizinho se preparando para uma apresentação de Moçambique.

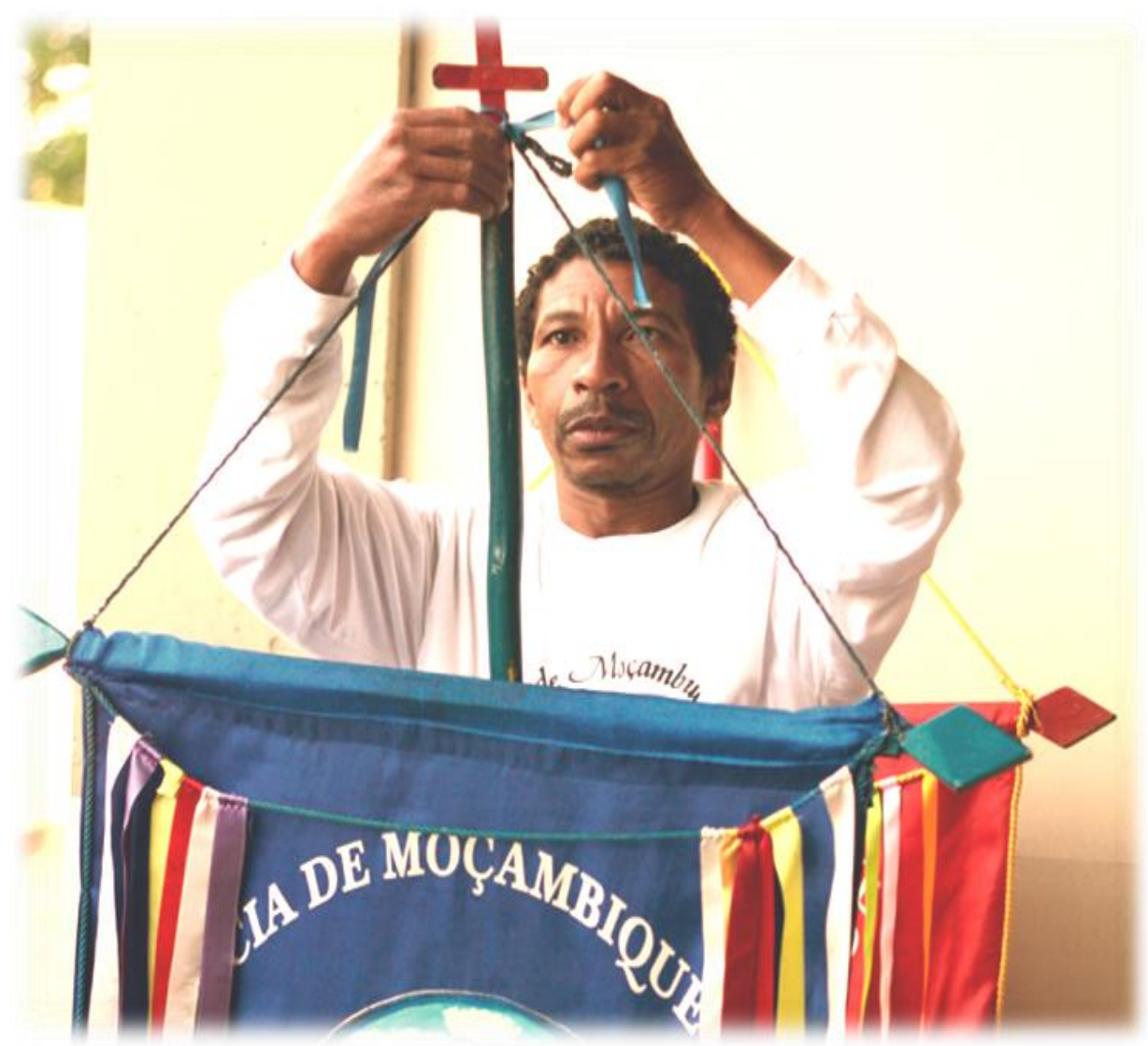

Fonte: Almanaque Urupês ${ }^{2}$.

Os colaboradores do presente estudo, embora de áreas de atuação distintas, dialogam por meio do mesmo pensamento sobre importância de se aliar cultura, cultura popular e educação. Quando abordados acerca do conceito de cultura popular, todos fazem menção à cultura como sendo parte da identidade de um povo. Dessa forma, ressalta-se o papel relevante do mestre Griot

\footnotetext{
${ }^{2}$ Disponível em: http://www.almanaqueurupes.com.br/portal/textos/artigos/o-mocambique/. Acesso em: 01 abr.
} 2018. 
no espaço escolar, cuja missão por ele referenciada, apresenta transferência de saberes por meio da dança. Assim sendo, atua de forma igualitária junto aos educadores no processo de aprendizagem das futuras gerações, e mesmo não sendo um educador formal detém os conhecimentos do saberfazer, de modo a exercer uma função (missão) que só indivíduos com essa bagagem ancestral conseguem e podem ministrar.

As entrevistas pautadas no método da História Oral, Meihy e Holanda (2017), abordaram diversas questões, dentre elas: cultura, cultura popular e a relação entre cultura e ambiente educacional. Mestre Paizinho menciona sempre a educação, mesmo sem ser indagado, demonstrando assim, a importância que a escola possui em sua história de vida:

A cultura popular é uma preciosidade e se a gente não unir a cultura e a educação, vai chegar um certo momento da trajetória da vida de um Mestre, que ela vai perdendo a sua essência. A cultura em si ela é maravilhosa, mas se a cultura em si, ela não for levada para a educação, pois as futuras gerações... elas são os nossos multiplicadores. E se a gente guardar a cultura só para si, ela não vai evoluir, mas quando a gente leva a cultura para educação, o trabalho de um Mestre ou de qualquer profissional da área cultural, aí então, a cultura com certeza vai ser mais respeitada e divulgada. (MESTRE PAIZINHO).

A gestora de uma instituição na qual foi realizada a observação de campo, ao ser indagada, respondeu:

Eu acho que o mais importante em trazer estas práticas para a escola, é fazer com que os educandos, seja de qual faixa etária que for, que eles possam vivenciar essas danças porque as danças populares, a cultura popular de uma maneira geral não é explorada, muitas vezes pela ligação com a religião, e as crendices populares são muito discriminadas por isso, está relacionada a isso, eu acho muito importante, muito importante mesmo! Fazer com que essas danças perdurem. (GESTORA I).

Reiterando a narrativa da gestora, observa-se a relevância de práticas concernentes à cultura popular por meio das danças populares. Conforme a recém homologada BNCC (2017), o Brasil é um país com vasto acervo cultural e os currículos escolares devem compreender essa exigência, elaborando propostas que atendam às necessidades e respeitem a diversidade presente no território Brasileiro. Sobretudo, é importante valorizar as singularidades, para que se possa promover a democratização do ensino, ressaltando que nos saberes peculiares é que se assegura a pluralidade. Desta feita, as vivências promovidas por Mestre Paizinho, também são possibilidades de desmistificar o conceito de vínculos religiosos atrelados às danças populares, pois, suas práticas 
são desprovidas de qualquer concepção religiosa. Sua abordagem é pautada na criatividade, auxílio ao desenvolvimento integral do discente, no respeito e na socialização. As vivências nas oficinas de Mestre Paizinho - que pratica o Moçambique por devoção - proporcionam uma experimentação que deixa marcas em uma pessoa de maneira duradoura; uma vez que o Mestre traz, para o interior da escola, uma possibilidade de trabalhar cognição, afetividade e psicomotricidade não envolvendo a perspectiva do Moçambique em devoção. Embora indiscutível, a questão da desigualdade social nos estabelecimentos formais de ensino brasileiros, a desmistificação de atividades de cunho artístico-culturais com objetivos pedagógicos é uma maneira de promover o ensino plural e igualitário. Os saberes inter-relacionais, quando articulados, promovem a chamada e almejada educação global.

Sobre o excerto acima, uma docente entrevistada discorre:

Eu acredito que é pouco trabalhado, são poucos os professores que optam por este caminho, por falta de conhecimento ou por falta de valorização mesmo, ou até mesmo por não ter tido isso, eu acho que poderia ser mais abrangente, pois daria muito mais sentido e significado para as crianças, pois desenvolveria o indivíduo de forma integral e também a identidade do aluno. (DOCENTE I).

É possível apreender, nos PCN de Educação Física, a importância das danças populares na práxis educativa, como ferramenta que pode promover a educação integral do indivíduo. Conforme complementa o documento:

Todas as culturas têm algum tipo de manifestação rítmica e/ou expressiva. No Brasil existe uma riqueza muito grande na colonização, danças relativas aos mais diversos rituais, danças que os imigrantes trouxeram em sua bagagem que foram aprendidas com os vizinhos de fronteiras [...] existem casos de danças que estão desaparecendo, pois não há quem as dance, quem conheça suas origens e significados. (BRASIL, 2001, p. 52).

Mestre Paizinho, além de ser um indivíduo consagrado por instâncias relevantes como o Ministério da Cultura é um ativista e gestor cultural. Possui vinte anos de trabalho, consolidado no município de origem. Mestre Paizinho realiza o Moçambique por devoção. A própria devoção não se esgota em si, mas movimenta o corpo, cantos e instrumentos, numa sincronia e unidade únicas. E nesse trajeto a escola é o campo de atuação e quando ele oferece a sua devoção à comunidade escolar, adequando-se ao ambiente disciplinador, ele transcende seus próprios valores para promover uma educação pautada na liberdade. Como orientam os documentos referentes aos temas transversais: conduzir para o interior dos estabelecimentos escolares relatos, tradições e atividades 
culturais é uma forma de perpetuar os conteúdos relacionados às danças populares - essa é a missão de Mestre Paizinho. Dialogando com a proposição elucidada por Ferreira (2009, p.16): “A dança Escolar deve possibilitar o resgate da cultura brasileira por meio da tematização das origens culturais, sejam do índio, do branco ou do negro, como forma de despertar a identidade do aluno no projeto de construção da cidadania"; deste modo, as oficinas ministradas por Mestre Paizinho são uma possibilidade de perpetuar este legado, e contribuem para uma Educação Física plural.

Logo, Retomando os objetivos do nosso trabalho no que se refere à análise das possibilidades pedagógicas das danças folclóricas brasileiras como um dos conteúdos da Educação Física escolar e a necessidade de ressignificação do gesto, constatamos que embora a escola básica tenha contribuído pouco no que diz respeito à propagação desses conhecimentos quando consideramos a atuação dos grupos familiares que transmitem oralmente esse patrimônio, entendemos que seja relevante destacar a necessidade de inserção do mesmo nos currículos, valorizando importantes traços culturais e identitários do nosso país, que podem ser reconhecidos e representados na escola. (FERNANDES; BRATIFISCHE, 2014, p. 112).

Assim sendo, conduz-se à reflexão sobre a complexidade e inúmeras possibilidades proporcionadas pelas danças populares. Dentre elas, o dizer da voz entoada por meio da gestualidade, a possibilidade de libertação de amarras corporais e a manutenção das raízes ancestrais. E nessa trajetória, é a escola, o berço das etnias, dos biótipos, das histórias e das culturas, o ambiente onde os (des) caminhos da cultura formal e informal devem estabelecer um diálogo harmonioso.

\section{A DESPEDIDA, CONSIDERAÇÕES FINAIS}

Retomando os objetivos centrais do estudo, vislumbra-se, por meio das narrativas dos sujeitos envolvidos, que as oficinas de Mestre Paizinho, não só promovem a valorização da cultura popular, como também fomentam a urgência em abordar conteúdos relacionados à cultura popular nos ambientes formais de ensino. As vivências de Moçambique promovidas na escola conduziram à reflexão sobre a relevante função social e cultural da Educação Física e conformam também o processo de identidade da cultura afro-brasileira.

Esse Universo pouco abordado, esse silêncio, presenciado por mim, no meu percurso acadêmico e profissional, instigaram-me ao desdobramento deste estudo. Questões pertinentes 
foram reveladas, reflexões foram suscitadas. Logo, com essas indagações acerca da pouca abordagem das danças populares no contexto da Educação Física, mesmo estando presentes nos documentos que respaldam os profissionais da área, bem como na literatura, deparei-me com Mestre Paizinho, sujeito simples, dotado de práxis pedagógica aprendida na escola da vida. Sem formação acadêmica, ele promove, com maestria, oficinas de danças populares na escola. A partir dessa constatação, surgiu, portanto, a sugestão de oferecer subsídios para os profissionais da área, sobretudo, para o meio acadêmico, tornando pública a invisibilidade do trabalho ministrado pelo Mestre.

Ao propiciar aos alunos a prática do Moçambique, no ambiente de educação formal, é possível desconstruir tabus elencados por meio de um processo cultural engessado e tradicional. As narrativas de Mestre Paizinho são dotadas de conteúdos de extrema maestria cultural e pedagógica, bem como de ações conscientes. Experiência e memória aliadas à percepção de sujeitos envolvidos - gestores e docentes - reiteraram a importância do trabalho de Mestre Paizinho, pois, provocaram reflexões acerca da valorização e promoção da dança popular nas aulas de Educação Física.

E que essa história, de um Mestre sem mestrado, cujo objetivo é de perpetuar o seu legado, fique pública, que novas iniciativas e reflexões tenham lugar, vinculadas a uma perspectiva de Educação Física Plural.

\section{REFERÊNCIAS}

ANDRADE, Mário. Danças dramáticas do Brasil. São Paulo: Martins, 1959.

BAUMAGRATZ, Jacqueline. Cultura popular do vale do Paraíba. São José dos Campos: Mogiana, 2011.

BOTELHO, Isaura. Dimensões da cultura: políticas culturais e seus desafios. São Paulo: Edições SESC São Paulo, 2016.

BRASIL. Diretrizes Curriculares Nacionais da Educação Básica. Brasília. Conselho Nacional de Educação.2001.

BRASIL. Base Nacional Curricular Comum. Brasília: MEC, 2017. Disponível em: http://basenacionalcomum.mec.gov.br/abase. Acesso em: 3 fev. 2018. 
BRASIL. Ministério de Educação e do Desporto. Secretaria da Educação Fundamental.

Parâmetros Curriculares Nacionais: terceiro e quarto ciclos: Apresentação dos Temas Transversais. Brasília: MEC/SEF, 1998.

BRASIL. Ministério da Educação e do Desporto. Secretaria da Educação Fundamental. Parâmetros Curriculares Nacionais: Educação Física. Brasília: MEC/SEF, 2001.

BRASIL. Ministério da Educação. Secretaria de Educação Fundamental. Parâmetros curriculares nacionais: pluralidade cultural. Brasília: MEC/SEF, 1997.

DAOLIO, Jocimar. Da cultura do corpo. Campinas: Papirus, 1995.

DARIDO, Suraya; Cristina; RANGEL, Irene. Conceição Andrade. Educação Física na escola: implicações para a prática pedagógica. Rio de Janeiro: Guanabara Koogan, 2005.

FERNANDES. Rita de Cássia; BRATIFISCHE. Sandra Aparecida. Possibilidades pedagógicas das danças folclóricas: gesto ressignificado nas aulas de educação física escolar. In: EHRENBERG, Mônica Caldas; FERNANDES, Rita de Cássia; BRATIFISCHE, Sandra Aparecida (Orgs.). Dança e educação física: diálogos possíveis. Várzea Paulista: Fontoura, 2014.

FOUCALT, Michael. A microfísica do poder. Rio de Janeiro: Edições Graal, 1979.

GOMES, Nilma Lino. Trajetórias escolares, corpo negro e cabelo crespo: reprodução de estereótipos ou ressignificação cultural? Revista Brasileira de Educação, São Paulo, n. 21, p. 40-51, 2006.

HOBSBAWN, Eric. A Invenção das Tradições (Introdução). In: HOBSBAWN, Eric e RANGER, Terence (Org.). A Invenção das Tradições. Tradução de Celina Cardim Cavalcante. Rio de Janeiro: Paz e Terra, 1977.

MEIHY, José Carlos Sebe Bom; HOLANDA, Fabíola. História oral: como fazer, como pensar. 2. ed. São Paulo: Contexto, 2017.

MELO, Marilene Carlos do Vale. A Figura do Griot e a relação memória e narrativa. In: LIMA, Tânia; NASCIMENTO, Izabel; OLIVEIRA, Andrey. (Org.). Griots - culturas africanas: linguagem, memória, imaginário. Natal: Lucgraf, 2009.

MEYER, Marlyse. Caminhos do imaginário no Brasil. 2. ed. São Paulo: Editora da Universidade de São Paulo, 2001.

NANNI, Dionísia. Ensino da dança: Rio de Janeiro: Shape, 2003.

OLIVEIRA, Eduardo David. Filosofia da Ancestralidade: corpo e mito na filosofia da educação brasileira. Curitiba: Editora Gráfica Popular, 2007. 
POZATTI, Mauro Luiz. A busca da inteireza do ser: formulações imagéticas para uma abordagem transdisciplinar e holística em saúde e educação. 2003. 153 f. Tese (Doutorado) Programa de pós-graduação em educação, Faculdade de Educação, Universidade Federal do Rio Grande do Sul, Porto Alegre, RS.

SILVA, René Marc da Costa (Org.). Cultura popular e educação salto para o futuro. Salto para o Futuro. Brasília: TV Escola/SEED/MEC, 2008. Disponível em:

http://www.pontaojongo.uff.br/sites/default/files/upload/livro_salto_cultura_popular_e_educacao i.pdf. Acesso em: 4 abr. 2018.

RIBEIRO, Maria de Lurdes Borges. Moçambique, cadernos do folclore. Rio de Janeiro: Europa gráfica e editora Lda, 1981.

STAKE, Robert Estake. Case Studies. In: DENZIN, N. K.; LINCOLN, Y. S. (Ed.). Handbook of qualitative research. London: SAGE Publications, 1994. p. 236-247.

TEIXEIRA. Rachel. Dias. Foi São Benedito quem me trouxe até aqui: devoção e tradição entre congadas e Moçambique do Vale do Paraíba. Rio de Janeiro: IPHAN, CNFCP, 2012.

Recebido em: 13 de setembro de 2018

Aceito em: 29 de novembro de 2019 